being carried out by Indian research assistants on Indian population groups in Johannesburg and Pretoria.

Death certificates suggest that South African Whites are probably as prone as overseas White populations to die from coronary heart disease. To give perspective to the electrocardiograph investigations on the Bantu, and to learn something of the incidence of myocardial ischæmia in representative local White populations with the co-operation of the authorities, electrocardiograph and other investigations have been carried out on 248 White persons. Assessment of tracings is still in progress. Permission from the relevant authorities has been obtained to carry out an investigation of 'total heart disease' in a group of workers-a study which will require intensive short-term co-operation from several physicians and other workers.

Other investigations have also shown the commonness of hypertension in the Bantu, a feature associated with a high incidence and mortality from cerebral vascular disease, but with virtually no mortality from coronary heart disease. In endeavours to throw light on hypertension in these people, a number of investigations have been carried out. Blood pressure and other investigations have been undertaken at schools previously visited for nutritional and biochemical studies in the Rustenburg, Hartebeestpoort and Witkoppen regions. It is apparent that blood pressure at one particular school is significantly lower than that of the others. Investigations on blood pressure have also been carried out on groups of mineworkers from different regions. Some differ. ences are apparent; for example, hypertension occurs less among Xhosa compared with Shangaan and Tswana Bantu.

Some Bantu groups are habituated to very soft water; others add plant ashes of variable composition to their food. There is one Bantu group, however, habituated to an unusually high intake of salt, the sole source of water (wells) having a salinity of about a quarter that of sea-water. This group, at Kukong, Southern Kalahari Desert, is being studied from the point of view of blood pressure, electrocardiograph, blood biochemistry and other aspects. Observations will be compared with those on another group dwelling nearby, but habituated to soft drinkingwater. This possibly unique natural situation should shed light on the influence of an unusually high intake of salt on hypertension in the Bantu.

\title{
EURYHALINE EUGLENOID FLAGELLATES
}

\begin{abstract}
A RECENTLY published pamphlet* is Part 8 of a series which, when completed, will be the first attempt to give a comprehensive account of the unicellular, mostly motile, algae occurring in British coastal and estuarine waters. It is the second part to appear, Part 1, containing the general introduction to the series, definitions, bibliography and the taxonomic section on Chlorophyceae having been published in 1959. Part, 8 consists of the taxonomic section on euryhaline Euglenineae. Since the series will deal with organisms of great importance for fishery and sea-food investigations, and since a taxonomic account of these organisms is not otherwise available, it is to be regretted that the pamphlet under review contains so many inaccuracies that its use cannot be recommended.

In the short description of the class Euglenineae with which the pamphlet begins there are omissions, misconceptions and several factual errors. For example, "Flagellum one or two" is incorrect for the Euglenineae, modern cytological studies having established the taxonomically important fact that all euglenoid flagellates have two flagella. Apart from the genera with two externally emergent flagella (for example, Distigma, Eutreptia, Peranema), most genera (for example, Astasia, Colacium, Euglena, Lepocinclis, Phacus, Trachelomonas) have one long flagellum which is emergent from the canal and functional in swimming. and a second flagellum which ends within the reservoir. This short flagellum is an independent organelle though its tip may be apposed to the longer flagellum, an arrangement which led to the old, erroneous description of a single flagellum bifurcate at the base. Other points needing correction are that emergent flagella with unilateral masti-

* Ministry of Agriculture, Fisheries and Food. Fishery Investiga tions, Series IV: An Introductory Account of the Smaller Algae of British Coastal Waters. Part VIII: Euglenophyceae $=$ Euglenineae. By Dr. R. W. Butcher. Pp. v+17+3 plates. (London: H.M. Stationery Office, 1961.) $12 s .6 d$. net.
\end{abstract}

gonemes have been demonstrated for more genera than those quoted, notably Phacus and Trachelomonas; colonial euglenoids are known, for example, Colacium mucronatum, which forms extensive dendroid colonies; members of the Euglenaceae and Astasiaceae are described as having "simple bilateral sym. metry" whereas one of the major taxonomic features of the euglenoid cell is its helical asymmetry; organisms in the Peranemaceae are said to have "complex dorsiventral organization" without the rider that such organization is found in species of most genera and is superimposed on the underlying helical asymmetry; the statement that "Euglena gracilis becomes colourless if grown in the dark" is misleading in its context, since permanent apochlorosis equivalent to the condition in Astasis is produced only if treatment with high temperature, ultra-violet irradiation, antihistamines or streptomycin is also applied; finally, Distigma cannot be said to be "the colourless counterpart of Eutreptia" in the way that species of Astasia might be for species of Euglena, or Hyalophacus is for Phacus.

Mistakes in the opening section are repeated in the key to the genera of the Euglenaceae (the only family dealt with in the pamphlet) and in the descriptions of genera and species. For example, the erroneous concept of species with only one flagellum appears several times and is carried to greater lengths for Euglena obtusa and $E$. vermiformis. $E$. obtusa is described as having "complete absence of a flagellum" when in fact it has two perfectly good flagella. It is true that in this species both flagella terminate within the reservoir at about the level of the eyespot. Dr. Butcher mentions a flagellar "vestige inside the canal" without apparently realizing its significance. As a practical point of distinction in the specific key it would be correct to say for $E$. obtusa "neither flagellum emergent" or, possibly, "no locomotory flagellum". 
The main text of the pamphlet contains now inaccuracies and misconceptions of which only the most obvious can be noted here.

It is undesirable to re-introduce Schiller's genera Ottonia and Chlorachne into the Euglenaceae when most authorities now exclude them entirely from the Euglenineae, especially since the descriptions of these organisms are merely repeated from Schiller's original records from the Adriatic.

Secondly, there is confusion in the section on Eutreptia where Dr. Butcher describes a new species, Eutreptia scotica, from matorial which I collected at Millport and gave him as a fresh isolation of Eutreptia viridis. Re-examination of my cultures of the Millport isolation shows this species to be cytologically identical with Prof. E. G. Pringsheim's isolation of $E$. viridis in the Cambridge Culture Collection, even to the extent of having the same chromosome count of 44. On the other hand, cells of $E$. perty $i$ supplied from Prof. Pringsheim's Sammlung von Algenkulturen, Göttingen, are considerably larger and cytologically more luxuriant than cells of $E$. viridis and the chromosome number, $90 \pm 2$, is approximately twice that of the smaller species. Yet Dr. Butcher finds his material of $E$. perty $i$ almost indistinguishable from the Cambridge $E$. viridis. From all this it seems probable that Dr. Butcher's "E. pertyi" is really $\boldsymbol{E}$. viridis, as is also his " $\mathbb{E}$. scotica", presumably described from Millport material in poor condition. The new species, $E$. scotica, cannot therefore be accepted.

Thirdly, an important error occurs in the section on Lepocinclis, where the reserve material is listed as "Ieucosin". Since the generic key states for Lepocinclis "2 ring-like paramylum grains always present" (itself not a true statement for all species of Lepocinclis), the introduction of the reserve material characteristic of the Chrysophyceae is presumably a slip of the pen, though it does occur five times.
Fourthly, descriptions of pyrenoids, particularly important in the classification of species of Euglena and Trachelomonas, are incorrect. The description of the double-sheathed pyrenoids typical of the Catilliferae group of the genus Euglena is inadequate, and there is nothing in Dr. Butcher's description to indicate that this pyrenoid structure occurs also in Trachelomonas hispida. The pyrenoids of $T$. volvocina are described as simple when they have, in fact, the taxonomically important structure referred to by Prof. Pringsheim as "inner pyrenoids", and $T$. zorensis is stated to have "pyrenoid absent" whereas it has good double-sheathed pyrenoids. The Trachelomonas species listed could certainly not be identified from the key and descriptions given.

Finally, the term "plastidome", strictly meaning the entire chromatophore complex of a cell, is wrongly used for the paramylum centres ("Paramylonherde" of Mainx) in Eutreptia, Euglena viridis and " $E$. schmitzii" (= E. geniculata).

The illustrations consist of a plate of paintings of colls and two plates of poor photographs which show nothing apart from the size and shape of the organisms. Surely what is needed in a taxonomic work provided with keys is a series of large drawings which can be aids to identification. The final photograph, purporting to show mastigonemes on flagella of Eutreptia pertyi, is unintelligible.

One appreciates the work involved in producing this taxonomic account of marine and brackish Euglenineae, and its major errors are listed above in the hope that future pamphlets in the series will achieve a higher standard of biological accuracy, especially since they are appearing as official publications of H.M. Stationery Office and will be read with this in mind by marine biologists throughout the world.

GORDON F. LEEDALE

\title{
THE ISRAEL SOUTH RED SEA EXPEDITION
}

\author{
BY O. H. OREN*
}

Director, Sea Fisheries Research Station, Haifa, and Deputy Leader of the Expedition

$\mathrm{M}$ ANY of the waters covering the globe have been extensively explored. One of the less explored and underexploited is the Indian Ocean. This fact and the desire to continue international and cooperative efforts and achievements during the International Geophysical Year led the United Nations to propose an International Indian Ocean Expedition. Many nations accepted the proposal, formed special committees and submitted national programmes for the exploration of this Ocean.

The Red Sea was not specifically included in the original programme. At a meeting of the Special Committee on Oceanic Research held in Copenhagen in summer 1960, the Israel representatives requested the inclusion of the Red Sea, as a part of the Indian Ocean, into the framework of the International Indian Ocean Expedition. This proposal was accepted provided that a National Programme for Red Sea exploration be submitted to the Special Committee on Oceanic Research.

* Compiled from notes by the following members of the Expedition: A. Abulafia, A. Ben-Tuvla, E. Clark, L. Fishelsohn, T. F. Goreau, T. B. Holthuts, Ch. Lewinsohn, Y. Nir, O. H. Oren, G. F. Papenfuss,
The reason for Israel's request was based on its more than ten years experionce in marine biological and fisheries research in the northern Red Sea. Israel has explored its $12-\mathrm{km}$. coast of the Gulf of Eilat (Gulf of Aqaba). During 1956-57, two parties of marine biologists had the opportunity of exploring the entire western coast of the Gulf of Eilat, Tiran and Sanaphir Islands, and around the Sinai Peninsula to Tor.

During 1957-58 exploratory fishing, leading to commercial fishery in recent years, was conducted from Massawa (Eritrea) in tho north and south Massawa Channols and in the vicinity of Kamaran Island by an Israeli fisheries research vessel and scientific personnel. Observations were made and vast material collected, part of which was examined and the rosults published in a special series ontitled "Contributions to the Knowledge of the Red Sea" in the Bulletin of the Sea Fisheries Research Station, Haifa.

Considerable interest in the exploration of the Red Sea was also shown by foreign scientists. By the time the Israol South Red Sea Expedition 1962 